\title{
Anesthetized Lethal Injection Intravenous Exsanguination Euthanasia
}

National Cancer Institute

\section{Source}

National Cancer Institute. Anesthetized Lethal Injection Intravenous Exsanguination

Euthanasia. NCI Thesaurus. Code C116222.

A method of euthanasia whereby a subject is anesthetized, a lethal chemical is administered by intravenous injection and the body is drained of blood. 